\title{
Does hand hygiene reduce SARS-CoV-2 transmission?
}

\section{Chao Yang ${ }^{1}$}

Received: 9 March 2020 /Revised: 9 March 2020 / Accepted: 19 March 2020 / Published online: 27 March 2020

(C) Springer-Verlag GmbH Germany, part of Springer Nature 2020

Tracy [1] share their experience of stepping up infection control measures in ophthalmology to minimize COVID19 infection of both healthcare workers and patients, and emphasize universal masking, hand hygiene, and appropriate use of personal protective equipment (PPE). However, whether hand hygiene is "particularly important" for SARS-CoV-2 infection control needs further study, as there is no convincing evidence that this prevention tool is effective in the SARS-CoV-2 epidemic.

Although there is evidence that hand hygiene can reduce respiratory diseases, it has not been proved that it can reduce SARS-CoV-2 transmission [2]. During the pandemic of influenza in 2009, Aiello et al. [3] determined the value of hand hygiene for influenza or influenza-like illness prevention, and found "hand washing habits were the same in both the face mask-only and control groups, which suggests that mask use alone may provide a reduction in respiratory illness regardless of hand washing practices." After adjustment for covariates, only the face mask with hand hygiene group showed a significant reduction.

The efficacy of hand hygiene in reducing transmission of influenza may be decided on one issue: Is SARS-CoV-2 virus spread primarily by large droplets or by small-particle aerosols? The more likely the virus transmitted by large droplets, the more likely that hand hygiene will reduce transmission. Hand hygiene may not be beneficial if small particle aerosol is the main route of transmission. There is evidence that tens of times greater quantities of virus are required for virus infection

Chao Yang

400843@hospital.cqmu.edu.cn

1 Department of Surgical oncology, National Clinical Research Center for Child Health and Disorders, Ministry of Education Key Laboratory of Child Development and Disorders, China International Science and Technology Cooperation Base of Child Development and Critical Disorders, Children's Hospital of Chongqing Medical University, 136 Zhongshan 2nd Road, Yuzhong District,

Chongqing 400014, China by intranasal drops than with aerosols [4]. Meanwhile, intranasal infection disease was milder than natural acquired disease; the duration of cough was also shorter.

In our opinion, the importance of hand hygiene cannot be overemphasized due to the absence of evidence revealing that hand hygiene reduces transmission of SARSCoV-2. Hand hygiene is of course a highly defensible measures, as SARS-CoV, MERS-CoV, and influenza virus can survive on surfaces for extended periods [5]. Another closely related human coronavirus, 229E, remained infectious on surface materials common to public and domestic areas for several days [6]. However, the cost of following this recommendation would be considerable, especially when extending the scope of measure to all people with risk of infection around the world. Furthermore, it should be noted that individuals may venture into crowds under the false illusion that hand hygiene can prevent them from acquiring or transmitting SARS-CoV-2 if we overemphasize hand hygiene, increased cases of COVID-19 would result. Additional studies are needed to determine whether hand hygiene is effectively to SARS-CoV-2 control.

\section{Compliance with ethical standards}

Conflict of interest The authors declare that they have no conflict of interest.

\section{References}

1. THT L, EWH T, SKY C, KSC F, KKW L (2020) Stepping up infection control measures in ophthalmology during the novel coronavirus outbreak: an experience from Hong Kong. Graefes Arch Clin Exp Ophthalmol. https://doi.org/10.1007/s00417-020-04641-8

2. Hota S, McGeer A (2007) Antivirals and the control of influenza outbreaks. Clin Infect Dis 45(10):1362-1368. https://doi.org/10. $1086 / 522661$

3. Aiello AE, Murray GF, Perez V et al (2010) Mask use, hand hygiene, and seasonal influenza-like illness among young adults: a randomized intervention trial. J Infect Dis 201(4):491-498. https://doi.org/ $10.1086 / 650396$ 
4. Alford RH, Kasel JA, Gerone PJ, Knight V (1966) Human influenza resulting from aerosol inhalation. Proc Soc Exp Biol Med 122(3): 800-804. https://doi.org/10.3181/00379727-122-31255

5. Otter JA, Donskey C, Yezli S, Douthwaite S, Goldenberg SD, Weber DJ (2016) Transmission of SARS and MERS coronaviruses and influenza virus in healthcare settings: the possible role of dry surface contamination. J Hosp Infect 92(3):235-250. https://doi.org/10. 1016/j.jhin.2015.08.027
6. Warnes SL, Little ZR, Keevil CW (2015) Human coronavirus 229E remains infectious on common touch surface materials. $\mathrm{mBio} 6(6)$ : e01697-e01615. https://doi.org/10.1128/mBio.01697-15

Publisher's note Springer Nature remains neutral with regard to jurisdictional claims in published maps and institutional affiliations. 